\title{
Erratum to: Nd:YAG laser irradiation associated with fluoridated gels containing photo absorbers in the prevention of enamel erosion
}

\author{
L. G. S Pereira ${ }^{1}$ - S. H. Joao-Souza ${ }^{1}$ - S. J. C. Bezerra ${ }^{1}$ - A. B. Borges ${ }^{2}$ • \\ A. C. C. Aranha $^{1}$. T. Scaramucci ${ }^{1}$
}

Published online: 20 June 2017

(C) Springer-Verlag London Ltd. 2017

Erratum to: Lasers Med Sci

DOI 10.1007/s10103-017-2226-6

The first author name was incorrectly captured. The given name and family name were interchanged. The correct name is shown in the author group section (above).

Correct version:

Given name: LGS

Last name: Pereira

The original article was corrected.

The online version of the original article can be found at http://dx.doi.org/ 10.1007/s10103-017-2226-6

\section{T. Scaramucci}

tais.sca@usp.br

1 Department of Restorative Dentistry, School of Dentistry, University of São Paulo, Av. Prof. Lineu Prestes 2227, São

Paulo, SP 05508-000, Brazil

2 Department of Restorative Dentistry, Institute of Science and Technology, São Paulo State University-UNESP, Av. Eng. Francisco Jose Longo 777, Jardim São Dimas, Sao Jose dos

Campos, SP 12245-000, Brazil 